\title{
Test Plan for Buried Waste Containment System Materials
}

\author{
J. Weidner \\ P. Shaw
}

Published March 1997

Idaho National Engineering Laboratory

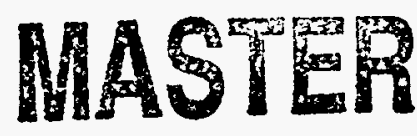

Lockheed Martin Idaho Technologies Company

Idaho Falls, Idaho 83415 
Test Plan for Buried Waste Containment System Materials

March 1997

Submitted by:

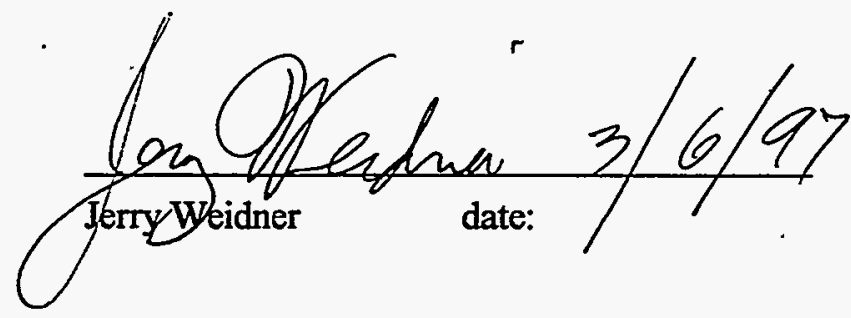

Document approval:
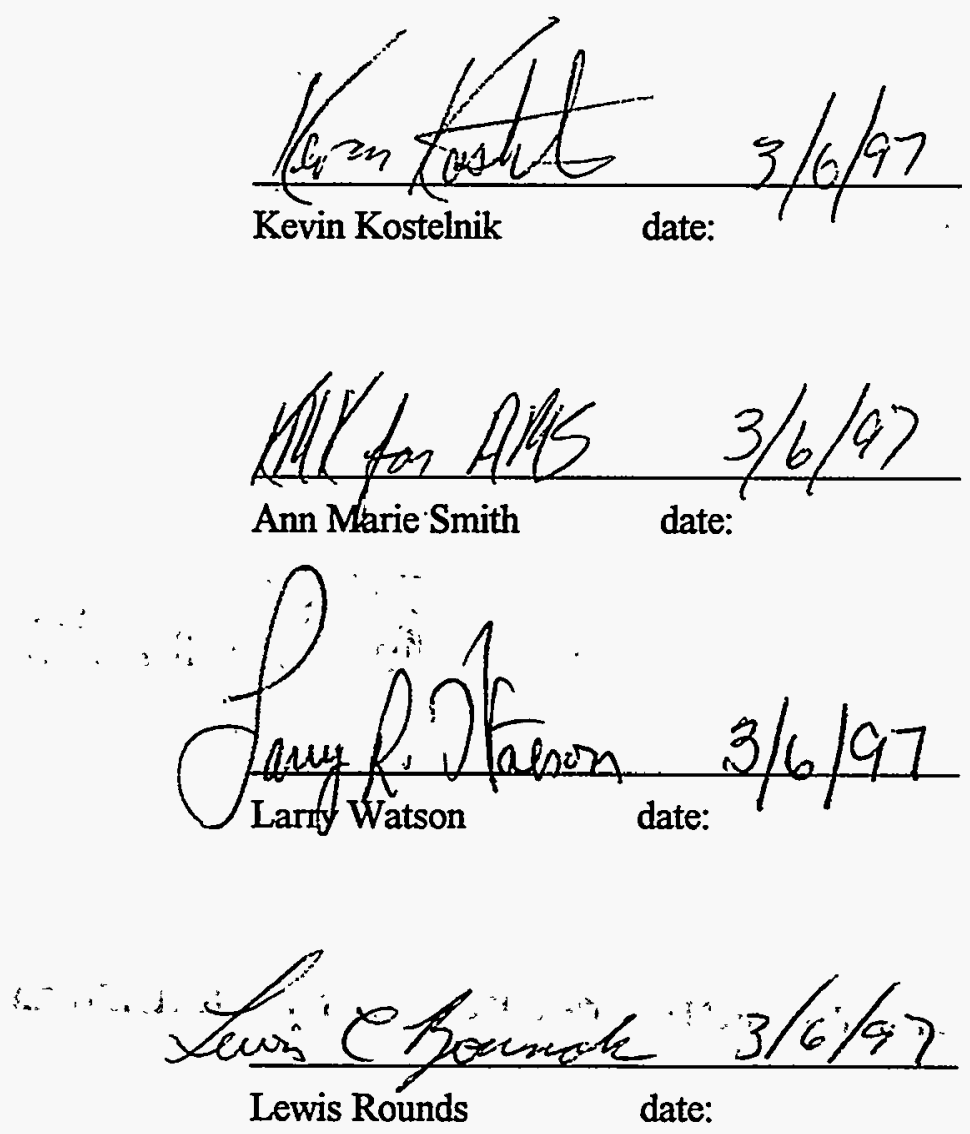

ii 
DISCLAIMER

Portions of this document may be illegible in electronic image products. Images are produced from the best available original document. 


\section{DISCLAIMER}

This report was prepared as an account of work sponsored by an agency of the United States Government. Neither the United States Government nor any agency thereof, nor any of their employees, make any warranty, express or implied, or assumes any legal liability or responsibility for the accuracy, completeness, or usefulness of any information, apparatus, product, or process disclosed, or represents that its use would not infringe privately owned rights. Reference herein to any specific commercial product, process, or service by trade name, trademark, manufacturer, or otherwise does not necessarily constitute or imply its endorsement, recommendation, or favoring by the United States Government or any agency thereof. The views and opinions of authors expressed herein do not necessarily state or reflect those of the United States Government or any agency thereof. 


\begin{abstract}
The objectives of the FY 1997 barrier material work at the Idaho National Engineering and Environmental Laboratory are to (1) select a waste barrier material and verify that it is compatible with the Buried Waste Containment System Process, and (2) determine if, and how, the Buried Waste Containment System emplacement process affects the material properties and performance (on proof of principle scale).

This test plan describes a set of measurements and procedures used to validate a waste barrier material for the Buried Waste Containment System. A latex modified proprietary cement manufactured by CTS Cement Manufacturing Company will be tested. Emplacement properties required for the Buried Waste Containment System process are: slump between 8 and 10 in., set time between 15 and 30 minutes, compressive strength at set of $20 \mathrm{psi}$ minimum, and set temperature less than $100^{\circ} \mathrm{C}$. Durability properties include resistance to degradation from carbonate, sulfate, and waste-site soil leachates. A set of baseline barrier material properties will be determined to provide a data base for comparison with the barrier materials when tested in the field. The measurements include permeability, petrographic analysis to determine separation and/or segregation of mix components, and a set of mechanical properties. The measurements will be repeated on specimens from the field test material. The data will be used to determine if the Buried Waste Containment System equipment changes the material.
\end{abstract}

The emplacement properties will be determined using standard laboratory procedures and instruments. Durability of the barrier material will be evaluated by determining the effect of carbonate, sulfate, and waste-site soil leachates on the compressive strength of the barrier material. The baseline properties will be determined using standard ASTM procedures. 


\section{CONTENTS}

ABSTRACT

CONTENTS $v$

ACRONYMS vii

1. PROJECT DESCRIPTION 1

1.1 Technology Agreement 1

1.2 Technology Description and Background 1

1.3 Selected Barrier Material 3

1.4 Scope of Laboratory Tests 3

1.5 Contingency Plan 4

2. ORGANIZATION AND RESPONSIBILITIES

3. TEST OBJECTIVES

3.1 Mix Formulation $\quad 8$

3.2 Initial Trials 9

3.3 Slump, Set Time, and Temperature Measurements 10

3.4 Compressive Strength at Set Measurements 11

3.5 Baseline Latex Modified Mortar Properties 11

4. QUALITY OBJECTIVES FOR CRITICAL MEASUREMENTS 12

5. SAMPLING PROCEDURES AND DATA COLLECTION 13

5.1 CERCLA Criteria 13

5.2 Data Collection Techniques 13

6. DOCUMENT CONTROL 14

6.1 Data 14

6.2 Test Plan 14

7. ANALYTICAL METHODS, CALIBRATION PROCEDURES, QUALITY 14

8. DATA REDUCTION, VALIDATION, AND VERIFICATION 15

8.1 Data Reduction Scheme $\quad 15$

8.2 Data Validation and Acceptance 15

9. QUALITY ASSURANCE 16

9.1 Data Quality Level and Inspection Requirements 16

9.2 Data Precision and Accuracy 16

10. EQUIPMENT AND INSTRUMENTS 16 
11. SUPPLIES, UTILITIES, AND FACILITIES

12. HEALTH AND SAFETY

13. RESIDUALS MANAGEMENT

14. REFERENCES

\section{FIGURES}

1. BWCS operational structure

\section{TABLES}

1. Buried Waste Containment System FY-97 project team

6

2. Proportions for initial test trials 


\section{ACRONYMS}

$\begin{array}{ll}\text { ASTM } & \text { American Society of Testing and Materials } \\ \text { BWCS } & \text { Buried Waste Containment Systems } \\ \text { CERCLA } & \text { Comprehensive Environmental Response, Compensation, and Liability Act } \\ \text { DOE } & \text { Department of Energy } \\ \text { DOE-ID } & \text { Department of Energy Idaho Operations Office } \\ \text { DOE-SR } & \text { Department of Energy Savanna River Operations Office } \\ \text { EPA } & \text { Environmental Protection Agency } \\ \text { ERT } & \text { Environmental Restoration Technology } \\ \text { INEL } & \text { Idaho National Engineering Laboratory } \\ \text { INEEL } & \text { Idaho National Engineering and Environmental Laboratory } \\ \text { IRC } & \text { Idaho Research Center } \\ \text { k } & \text { hydraulic conductivity } \\ \text { LMITCO } & \text { Lockheed Martin Idaho Technologies Company } \\ \text { MSDS } & \text { manufacturer safety data sheet } \\ \text { NITS } & \text { National Institute of Technology and Science } \\ \text { NRC } & \text { Nuclear Regulatory Commission } \\ \text { OWTD } & \text { Office of Waste Technology Development } \\ \text { pH } & \text { negative logarithm of hydrogen activity } \\ \text { PI } & \text { principal investigator } \\ \text { PM } & \text { project manager } \\ \text { POP } & \text { proof of principal } \\ \text { QA } & \text { quality assurance } \\ \text { RAHCO } & \text { R. A. Hanson Company, International } \\ \text { RWMC } & \text { Radioactive Waste Management Complex } \\ \text { RCRA } & \text { Resource Conservation and Recovery Act } \\ \text { SBR } & \text { styrene butadiene rubber } \\ \text { SCFA } & \text { Subsurface Contaminant Focus Area } \\ \text { SDA } & \text { Subsurface Disposal Area } \\ & \end{array}$




\title{
Test Plan for Buried Waste Containment System Materials
}

\author{
1. PROJECT DESCRIPTION
}

\subsection{Technology Agreement}

The laboratory testing of the barrier materials to support the Buried Waste Containment System (BWCS) program is being performed under TTP-ID-77SS21.

\subsection{Technology Description and Background}

\subsubsection{Test Plan Scope}

This test plan describes the laboratory test program to validate a latex modified cement formulation to be used with the BWCS process during a proof of principal (POP) demonstration. Styrene butadiene rubber (SBR) modified cement was chosen because it is known to perform very well in aggressive environments ${ }^{9}$ and is expected to have the physical properties necessary for this application.

The primary thrust of the test program described here is to validate the barrier material mix formulation to be used with the BWCS equipment. A basic mix formula for initial trials has been supplied by the cement and latex vendors. This formulation will be verified by INEL laboratory testing and, if necessary, will be adjusted to meet the application requirements.

The test program includes obtaining a set of baseline laboratory measurements including hydraulic conductivity, petrographic analysis, and a set of mechanical property tests typical of concrete characterization. These measurements will establish a data base for comparison with the properties of the barrier material used for field testing.

A POP demonstration using the R. A. Hanson Company (RAHCO) International equipment and the SBR modified cement will be performed in the spring of 1997. At that time, additional evaluation of the performance and properties of the barrier material will be made, including field hydraulic conductivity measurements. Samples will be collected for comparison with the laboratory baseline testing. An identical suite of measurements will be made to determine whether the BWCS equipment and processes have affected the material However, the field activities are not part of the test program described here.

\subsubsection{BWCS Description and Barrier Material Application Requirements}

The BWCS is a technology for fabricating a trough-shaped, in situ, waste containment barrier beneath a waste site. The bottom of the trough would be about $40 \mathrm{ft}$ wide and have a thickness of $1 \mathrm{ft}$. The 
depth to the trough bottom would be $20 \mathrm{ft}$. The trough sides would be vertical or sloped outward and have a thickness of about 6 in. The trough material is to provide an impermeable barrier to contaminant migration and therefore the material must have virtually zero crack density at the field scale and a hydraulic conductivity of $10^{-7} \mathrm{~cm} / \mathrm{sec}$ or less as measured in the laboratory. The shape of the structure and the low crack density require the material to have either very small volume change during set and cure, or that the material be capable of some plastic deformation without cracking. The BWCS process and placement equipment also impose some constraints on the physical properties of the material and the setting process.

1. The requirement for set time is $\mathbf{1 5}$ minutes minimum to $\mathbf{3 0}$ minutes maximum, and is the time required to develop a compressive strength of $20 \mathrm{psi}$.

2. The compressive strength (ASTM C 39) at set must exceed 20 psi to support the soil overburden during the grouting process. This number is a conservative estimate based on an assumed soil overburden density of $1.6 \mathrm{gm} / \mathrm{cm}^{3}$. The load produced by the overburden at a depth of $20 \mathrm{ft}$ would then be about $14 \mathrm{psi}$. In the case of buried waste typical of the Radioactive Waste Management Complex (RWMC), the average density would be reduced from the assumed $1.6 \mathrm{gm} / \mathrm{cm}^{3}$ to $1.2 \mathrm{~m} / \mathrm{cm}^{3 .(6)}$ The term set time as used in this test plan is that time at which the cement mixture achieves a compressive strength of $20 \mathrm{psi}$.

3. Set temperature is to be less than $100^{\circ} \mathrm{C}$.

4. Slump (ASTM C 143) is to be 8 to $10 \mathrm{in.}$

5. Aggregate particle size must be in accordance with ASTM C 144.

\subsubsection{Barrier Material Durability Requirements}

The barrier material will be applied to a waste site in an arid environment in the FY-98 and FY-99 field tests and therefore should have chemical properties that are compatible with the soil and ground water typical of arid climates. Therefore the barrier material must be:

1. Resistant to chemical attack in solutions saturated with calcite, $\mathrm{CaCO}_{3}$ (i.e., high $\mathrm{CO}_{2}$ ), and gypsum, $\mathrm{CaSO}_{4} * 2 \mathrm{H}_{2} \mathrm{O}$ (i.e., high $\mathrm{SO}_{4}$ ), typical of caliche deposits in arid region soils.

2. Resistant to chemical attack in contact with solutions extracted from the waste site soil.

Because of the depth below land surface, wet-dry and freeze-thaw effects are much less important and will not be determined as part of this test program. 


\subsection{Selected Barrier Material}

Styrene butadiene rubber (SBR) i.e., latex, modified Rapid Set cement was selected as the most reasonable candidate material for the BWCS POP application. The SBR material is a commercially available commodity used in the construction industry and has also been tested for waste barrier application. ${ }^{(4)}$. The latex provides low permeability, high adhesion, resistance to chemical attack, ${ }^{(9)}$ as well as resilience and resistance to crack formation. Rapid Set cement, a proprietary material manufactured by the CTS Cement Manufacturing Company, was chosen because it has minimal shrinkage, a set time less than 30 minutes without the addition of special accelerators, and has been tested with the SBR admixture. Compared to exotic materials such as polysiloxane, ${ }^{(1)}$ latex modified cement is preferred for this application because it has workability properties similar to conventional cement, is hazard free and environmentally safe, is easily cleaned up with water, and is expected to have satisfactory long term durability properties. ${ }^{(4)}$

\subsection{Scope of Laboratory Tests}

This test plan describes the laboratory test program for obtaining the formulation of latex modified Rapid Set cement as the barrier material to be used with the BWCS process during a POP demonstration. The approach to be used is to start with a formulation recommended by the manufacture for the intended application and to adjust the composition until the BWCS performance requirements listed in section 1.2 are achieved or it is learned that they can not be achieved.

Durability tests will be performed to asses the affect of carbonate, sulfate, and test site soil leachates on the performance of the barrier materials.

A set of baseline laboratory measurements, including hydraulic conductivity, petrographic analysis, and a set of mechanical property tests typical of concrete characterization, will also be conducted as part of this test program. These measurements will establish a data base for comparison with the barrier material used for field trials.

\subsubsection{Test Schedule}

The schedule of specific laboratory activities is as follows:

December 1, 1996

March 6, 1997

March 12, 1997

March 16, 1997

March 17, 1997

April 12, 1997

April 28, 1997
Complete draft test plan

Complete review and revisions to test plan

Complete procurement of materials and equipment

Readiness review

Initiate laboratory testing

Complete laboratory testing

Issue draft final report. 


\subsection{Contingency Plan}

The contingency plan includes alternative procedures for the possible failure of the following elements of this program. Implementation of the contingency plan is not expected to affect the cost or success of the project.

\subsubsection{Unavailable Resources}

The sample preparation responsibilities, viscosity measurements, sample set time and temperature measurements, can be performed by A. Glenn (preferred), P. Shaw, or J. Weidner. Compressive strength measurements will be conducted at the Idaho Research Center (IRC). Several personnel are trained to make these measurements. The baseline tests can be done in commercial concrete testing laboratories.

\subsubsection{Unacceptable Material}

The contingency plan also includes the testing of an alternative barrier material, namely SBR modified Portland type III cement. Testing of the alternate material will be performed in parallel with the rapid Set based material through the initial trials (see Section 3.2).

\section{ORGANIZATION AND RESPONSIBILITIES}

The project is under the Subsurface Contaminant Focus Area (SCFA) program with LockheedMartin Idaho Technology Company (LMITCO) being the primary company in partnership with RAHCO International. LMITCO will provide overall project engineering, project management, scientists, and laboratory space. The BWCS operational structure is shown in Figure 1. The complete BWCS project team is listed in Table 1.

Ann Marie Smith is the principal investigator (PI) and will also carry out project management to ensure that milestones are met, scope is sufficient, work is done within budget, and reports are submitted to SCFA and the Department of Energy (DOE) customer. Required changes in project scope and/or budget will be identified in a timely manner and appropriate action will be taken. Smith will monitor the progress of the work by direct contact with the appropriate personnel and will report the progress of the work through weekly and monthly reports.

The scientist responsible for the laboratory testing of barrier material is Jerry Weidner He is responsible for meeting the technical scope, and ensuring the data obtained are within the frame work provided by this test plan, are defensible, and of high quality. Scientists assisting with the test program are Peter Shaw and Ann Glenn. The laboratory activities will be performed by Shaw and Glenn.

In general, the level of training required is basic chemical laboratory skills and experience dealing with chemical research. The level of training required for the operation of each instrument is that the operator be capable of conducting research, including all necessary instrument usage and calibration. 


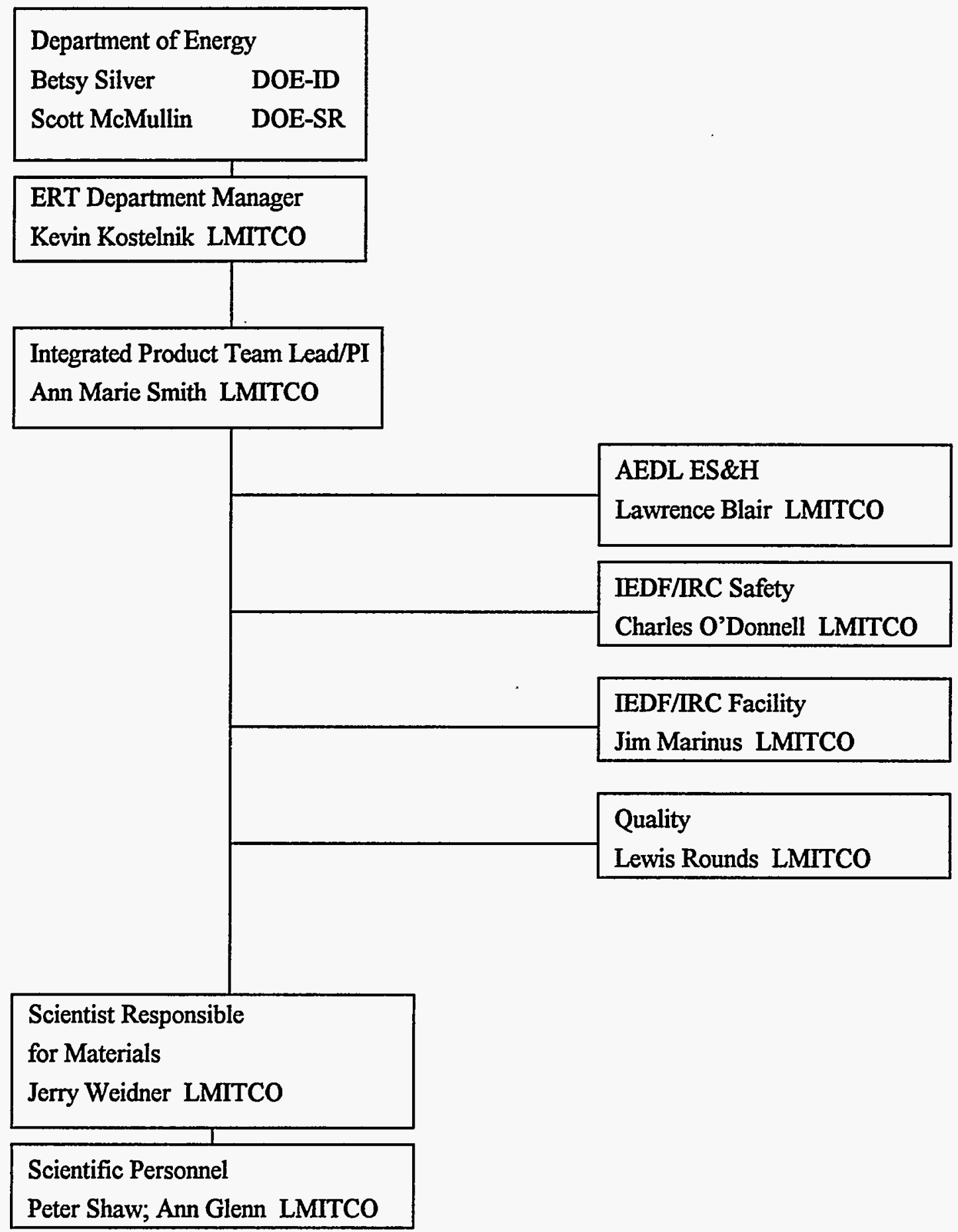

Figure 1. BWCS operational structure. 
Table 1. Buried Waste Containment System FY-97 project team

\begin{tabular}{llllll}
\hline Name & E-Mail & Phone & Mailstop & Fax
\end{tabular}

DOE

Betsy Silve
Scott
McMullin

Silverbs

208-526-9855

1219

208-526-6249

DOE-ID

scott.mcmullin 803-725-9596

803-725-2123

DOE-SR

@srs.gov

Greg Lancaster

John Nonte

Judy Partin

John

Richardson

GDL4 .

NONTJA

JK6

JGR

SGP

AQS

Ann Marie

Jerry Weidner

Larry Whitmill

WEI

WIT

\section{COMMON}

\section{SUPPORT}

Audrey Dineen

Marsha

Gunderson

Kevin

Kostelnik

Judy Mitte JYM

Mike Peters MDP

Lewis Rounds RCL

Larry Watson

LYW

ASH

MG4

KVK

$\begin{array}{ll}208-526-1190 & 2211 \\ 208-526-5370 & 3750 \\ 208-526-2822 & 2211 \\ 208-526-2387 & 3710 \\ & \\ 208-526-5917 & 3710 \\ 208-526-6877 & 3765 \\ 208-526-1297 & 2107 \\ 208-526-0357 & 3765\end{array}$

3710

3710

3710

208-526-0514 3710

208-526-7555 3710

208-526-0063 3710

208-526-2232 3710

\section{RAHCO}

Tom Crocker

Rick Hodges
509-467-0770

509-467-0770

509-467-0770
208-526-2814 Sens

208-526-4313 Site

208-526-2814 Sens

208-526-6802 Site

208-526-6802 Material

208-526-0425 PI/PM

208-526-0875 Material

208-526-0425 Mech
208-526-6802 Tracking

208-526-6802 Secretary

208-526-6802 Manager

208-526-6802 Prog Control

208-526-6802 Marketing

208-526-6802 Quality

208-526-6802 ES\&H
509-466-0212 Manager

509-466-0212 Lead

509-466-0212 Mech 


\section{TEST OBJECTIVES}

The objectives of the tests and measurements described in this test plan are to provide a proper formulation of a waste containment barrier material for use with the BWCS process in an arid environment and to determine whether the BWCS process and equipment affect the properties of the barrier.

An SBR modified Rapid Set cement formulation recommended by the cement and latex manufactures will be used for initial trials. The objective of the procedures is to produce a barrier mix formulation having the following properties:

1. Set time must be between 15 and 30 minutes.

2. Temperature during set must be less than $100^{\circ} \mathrm{C}$.

3. Slump must be between 8 and 10 in., measurement made according to procedure ASTM C 143.

4. Compressive strength at set must be greater than 20 psi, measurement made according to procedure ASTM C 39-86.

If the initial trials show that the formulation produces a material within the specifications for emplacement given above, then compatibility/durability tests will be conducted. If the initial trials produce a material that does not meet the emplacement requirements, then the tests will be repeated using modified formulations. The changes in the formulation (proportions of water, cement, latex, and aggregate, and if necessary, added retardant or accelerator) will be made as recommended by the manufacture to achieve the desired performance goals or as directed by the PI in the absence of manufacture recommendation.

The durability testing of the product will allow the effect of carbonate, sulfate, and site soil leachates to be assessed. The compatibility/durability testing will provide preliminary data to evaluate the effect of adverse chemical environments, typical of arid climates, on the compressive strength of the cured latex modified cement and will include evaluation of the effect of carbonate, sulfate, and waste-site soils.

A set of baseline laboratory measurements, including hydraulic conductivity, petrographic analysis, and a set of mechanical property tests typical of concrete characterization, will also be conducted. These measurements will establish a data base for comparison with the field performance of the barrier material. The baseline measurements will be repeated on specimens collected from BWCS field trials. The affect of the BWCS equipment on the barrier material properties will be determined by comparing the two data sets. All of the baseline measurements will be performed according to the appropriate ASTM procedure.

The test objectives will be met by using the materials, equipment and methods described below. 


\subsection{Mix Formulation}

\subsubsection{Starting Materials}

The materials used to formulate the latex modified Rapid Set cement mixtures shall be made up of the following :

1. Rapid Set cement manufactured by CTS Cement Manufacturing Company.

2. Latex cement additive Modifier A, with nominal $47 \mathrm{wt} \%$ solids, manufactured by Dow Chemical Company.

3. Mortar sand, ASTM C 144, oven dry. Undried sands may be used if the moisture per unit weight is determined by weight loss at $105^{\circ} \mathrm{C}$ and the water is included in the total water amount.

4. Water may be any potable water.

The materials used to formulate the latex modified Portland cement type III test mixtures shall be made up of the aggregate and water listed above plus the following:

1. The latex polymer is to be Tylac 68014 with anti-foam manufactured by Reichhold Chemicals Inc. ${ }^{(4)}$ or equivalent.

2. Cement is to be ASTM type III cement.

3. Technical grade calcium chloride or other set accelerator as specified by the latex manufacture.

\subsubsection{Starting Material Proportions}

\subsubsection{Latex Modified Rapid Set.}

The proportion of the materials in the latex modified Rapid Set cement mixture will be made up according to the cement manufacture recommendations with the concurrence of the PI and RAHCO International counterpart. The cement manufacture, CTS Cement Manufacturing Company, recommended the following proportions for initial test trials. Sand concentration adjustments will be based on the results of the initial trials. Further mix adjustments will be made according to the recommendation of the manufacture to produce the desired material. In the following mixture, the proportions are given in the ratio to 100 parts Rapid Set cement by weight, except for the aggregate which is the ratio according to volume. 
Table 2. Proportions for initial test trials.

\begin{tabular}{lll} 
Cement to mortar sand & proportion & $\begin{array}{l}1 / 3 \text { cement to } 2 / 3 \text { mortar sand by } \\
\text { volume }\end{array}$ \\
Polymer & $\begin{array}{l}\text { according to the solids in the } \\
\text { analysis provided by the } \\
\text { manufacture }\end{array}$ & $\begin{array}{l}15 \text { parts by weight of polymer } \\
\text { solid }\end{array}$ \\
Total water & $\begin{array}{l}\text { adjusted by trial to achieve the } \\
\text { desired mixture, and includes the } \\
\text { surface water of the aggregate } \\
\text { and the water in the latex }\end{array}$ & approximately 30 parts by weight \\
\hline
\end{tabular}

\subsubsection{Mixing Test Material}

The required amount of cement and aggregate will be dry blended by hand, or by using a simple cylindrical roller mill or similar device as appropriate. Water is then added and blended using a slow turning electric mixer. The latex is added after the water has been mixed and the mix appears homogeneous. It is possible that water alone will not produce a workable mixture. If so, the water and latex should be mixed and then added to the dry cement-aggregate blend. A description of the mixing procedure will be recorded in the laboratory note book. All mixing times will be measured and recorded in the laboratory notebook.

\subsection{Initial Trials}

The initial trials consist of a set of qualitative observations of freshly prepared mixtures. The object is to estimate the workability and set time of several slightly different formulations of the barrier materials, namely the effect of water content on workability and the length of time required for the prepared mixtures to change from a plastic material to a firm, load-supporting material.

Thirty parts total water is the recommended quantity for initial trials (see section 3.1.2) using the Rapid Set cement. Mixtures with three different water contents will be prepared for initial tests. These shall contain 37 parts water, 30 parts water, and 23 parts water, all other variables being held constant. Each of the prepared mixtures will be placed within a small, unsealed, plastic household food container, (i.e., an unsealed 4 by 4 in. plastic bag or similar unsealed envelope-like plastic container), and placed on a hard surface such as a laboratory bench to cure. It is important that the container be open to the atmosphere so that the latex can cure. Laboratory temperature and laboratory relative humidity shall be recorded.

The mixtures shall be examined and the observations recorded in the laboratory notebook (such as general appearance, plasticity, firmness, heat generation, fluidity, free water, ability to free stand). 
Observation shall be made and recorded in the laboratory notebook every minute for the first 20 minutes and every 5 minutes for the following 2 hours. After 2 hours, the PI will determine if systematic observation are to continue, otherwise the test specimens will be labeled and stored for future reference.

These data will be used to estimate the workability and set time of the test mixtures. If the test mixture does not meet design goals, the PI will select new mixture compositions, including accelerators or retardant, as recommended by the latex manufacture, for testing.

Mixtures using the Portland ASTM type III cement will be prepared and examined in a manner identical to that described for Rapid Set cement. Water contents to be used are 23, 17, and 12 parts per 100 parts cement by weight, all other variables being held constant. Mix formulation will be according to manufacture's specifications.

On the basis of the data collected, the PI will select the material, either Rapid Set or Portland ASTM type III cement, for the quantitative measurements described below.

\subsection{Slump, Set Time, and Temperature Measurements} conducted.

After the initial trials have established the barrier material composition, the following tests will be

Material performance requirements include set time between 15 and 30 minutes, compressive strength at set to be 20 psi or greater, set temperature less than $100^{\circ} \mathrm{C}$, and mixture slump to be between 8 and $10 \mathrm{in}$. The following procedure will show whether the mixtures meet the design specification.

Immediately after mixing, the properties of the latex mortar material are measured as a function of time using a Brookfield digital viscometer model DV-II+ according to the manufacture's instructions. Mix temperature, viscosity, shear rate, shear stress, and rotational speed will be measured and recorded as a function of time. The tests will be repeated four times to determine the precision of the measurements. These data will be used to estimate the set time and temperature of the test mixture. If the test mixture does not meet design goals, the PI will select new mixture compositions, including accelerators or retardants as recommended by the latex manufacture, for testing. Laboratory temperature and relative humidity during testing shall be recorded in the laboratory notebook.

After set time and temperature have been established, the slump of the latex grout materials will be measured according to procedure ASTM C 134. The tests will be repeated four times to determine the precision of the measurements. These data will be used to estimate the slump of the test mixtures. If the test mixture does not meet design goals, the PI will select new mixture compositions, including accelerators or retardants, as recommended by the latex manufactures, for testing. Laboratory temperature and relative humidity during testing shall be recorded in the laboratory notebook. At any point the materials fail testing, the formula will be altered and the complete series of tests will be repeated. 


\subsection{Compressive Strength at Set Measurements}

The requirement - compressive strength at set greater than $20 \mathrm{psi}$ - will be determined. After the set time and slump have been estimated, molds of Lexan or similar material, 1-in. diameter and 2-in. length will be used to fabricated 28 latex modified mortar cylinders for compressive strength at set measurements and durability tests. The test mixture will be prepared, placed into molds, and allowed to set at laboratory temperature, pressure, and relative humidity. Compressive strength (ASTM C 39) of twelve samples will be measured, four sample cylinders each at 5 minutes, 20 minutes, and 80 minutes after the previously determined set time. Laboratory temperature and relative humidity will be recorded in the laboratory notebook. The remaining test cylinders will be used for durability tests. They shall be stored in a controlled environment, $60^{\circ} \mathrm{F}$ and $70 \%$ relative humidity, to approximate subsurface conditions, for 28 days.

\subsubsection{Waste Compatibility Tests and Compressive Strength Tests}

After the 28-day cure time, four of the cylinders will be used to measure the compressive strength of the test barrier material according to ASTM C 39. Four cylinders will remain in the controlled environment as a standard for comparison. Waste compatibility immersion testing will be performed using the remaining eight cylinders. The test will be done by suspending four cylinders of the test material in chemically inert containers containing solution saturated with a mixture of laboratory grade $\mathrm{CaCO}_{3}$ and $\mathrm{CaSO}_{4} * 2 \mathrm{H}_{2} \mathrm{O}$, and four identical cylinders suspended in an aqueous solution/ suspension using soil from the test site. The solids in the containers will be agitated to maintain chemical equilibrium and the $\mathrm{pH}$ of the solutions will be measured and recorded on a daily basis for 28 days. Any changes in the physical nature of the cylinders, such as cracks, swelling, and precipitates will be noted and recorded in the laboratory notebook. At the end of the 28 day time period, the compressive strengths of the immersion samples together with the comparison samples from the controlled environment will be measured using the same procedures as described in Section 3.3. The fractured samples will be examined using the unaided eye, hand lens, low power microscope. The texture and microstructure will be described and recorded in the laboratory notebook.

\subsection{Baseline Latex Modified Mortar Properties}

A set of baseline laboratory measurements, including hydraulic conductivity, petrographic analysis, and a set of mechanical property tests typical of concrete characterization, will be conducted. These measurements will be repeated on barrier material specimens from the BWCS field demonstration. These measurements will be used for comparison with the field performance of the barrier material. The baseline measurements will be done at the Idaho national Engineering and Environmental Laboratory (INEEL) concrete testing laboratory located at the Central Facilities Area. 


\subsubsection{Permeability Tests}

Flexible wall permeability tests will be performed to determine the hydraulic conductivity $(k)$ of the latex modified cement materials and will be performed in accordance with ASTM D 5084-90, the standard test method for measuring $k$ of saturated porous materials using a flexible wall permeameter with a falling headwater/rising tailwater evaluation. Four test specimens will be measured. The test specimens will be prepared in molds of Lexan, or similar material. Dimensions of the molds will be chosen to be compatible with the permeameters to be used. This is to be determined by consultation with the laboratory that will perform the measurements. The test mixture will be prepared (Section 3.1.3 above), placed into molds, and allowed to set at laboratory temperature, pressure, and relative humidity. The test cylinders shall be stored in a controlled environment, $60^{\circ} \mathrm{F}$ and $70 \%$ relative humidity for 28 days prior to the permeability measurements.

\subsubsection{Petrographic Analysis}

Petrographic analysis will show the distribution of sand particles, cement, latex, and air (void) space within prepared cylinders of latex modified cement. These data will be used to evaluate separation and segregation of the barrier material components. Measurements will be conducted according to the procedures in ASTM C 856-95. Four test specimens will be measured. The test specimens will be prepared at the same time and in an identical manner to the permeability test specimens (Section 3.5.1).

\subsubsection{Mechanical Property Tests}

A set of mechanical property tests will be performed to establish the baseline mechanical properties of the material. This data will be used as a standard of comparison for similar measurements done on material prepared under field conditions. The test include the following:

- $\quad$ Compressive strength test according to ASTM C 39

- Tensile strength test according to ASTM C 496

- $\quad$ Porosity, specific gravity, air void tests, according to ASTM C 642

- Creep test and modulus of elasticity according to ASTM C 469

- $\quad$ Flexural test according to ASTM C 78.

Four specimens will be measured for each test. The test specimens will be prepared in an identical manner to the permeability test specimens (Section 3.5.1) and stored in a controlled environment, $60^{\circ} \mathrm{F}$ and $70 \%$ relative humidity, for 28 days prior to the measurements.

\section{QUALITY ASSURANCE OBJECTIVES FOR CRITICAL MEASUREMENTS}

The objective of the initial trial set of observations (Section 3.2) is to quickly eliminate unsuitable 
compositions from further consideration. Simple qualitative observations of the material properties, particularly the plastic state and the firm state and the time required for the change from plastic to firm, are required. The passage of time will be measured with a precision of $10 \%$ of the appropriate time unit, i.e., minute would be measured to \pm 6 seconds, and hour measured to \pm 6 minutes.

After the initial trials have been completed, a set of quantitative measurements will be taken to confirm that the selected compositions meet the design requirements. The critical properties of the materials to be tested include slump between 8 and 10 in.; set temperature less than $100^{\circ} \mathrm{C}$; set time between 15 and 30 minutes; and 20 psi minimum compressive strength at set. All measurements will be repeated four times. Material weights will be determined to \pm 1 weight percent of the amount required on an electronic or other appropriate balance. Compressive strength, viscosity, temperature, relative humidity, and time, will be measured with a precision of $\pm 1 \%$. Slump will be measured with a precision of $\pm 10 \%$. Instruments used for quantitative measurements will be calibrated and approved by the Standards and Calibrations Laboratory or by the manufacture. Back up material samples will be made for archival samples and display purposes and will be placed in sealed bags and labeled with date and log book serial number. All pertinent data for that sample will be noted in the logbook and will include sample identification number, material composition, date, time, notes, and observations.

Qualitative data taken will not be subject to rigorous statistical analysis but will be recorded and documented through log book entries, photographic evidence, and video tapes as appropriate. A certificate of compliance will be provided by the suppliers of the latex, cement, and sand used to prepare the test mixtures.

\section{SAMPLING PROCEDURES AND DATA COLLECTION}

\subsection{CERCLA Criteria}

CERCLA Criteria are not applicable to the test program described in this test plan. CERCLA Criteria are applicable to remediation technology alternatives, but are not applicable to single component testing.

\subsection{Data Collection Techniques}

Data will be collected according to standard laboratory procedures. Typically data collection techniques involve either measurements using specific instruments according to the instrument manufacture recommendations or are qualitative observations such as the presence of cracks and sample swelling. Description of test procedures are given in Section 3 or referenced ASTM procedures. 


\section{DOCUMENT CONTROL}

\subsection{Data}

All laboratory data and observations will be recorded in a bound, library registered laboratory notebook. It will be dated and signed daily by the person doing the experiments. Entries will be quality assurance (QA) checked and signed daily by a second person. All reagent labels are recorded completely in the notebook and are photographed for record. All laboratory activities will be photographically documented. A second bound, library registered laboratory notebook will be used to record date, time, subject, and photograph film frame number for each photograph. It will also be signed daily by the person doing photographs and entries will be QA checked and signed daily by a second person.

When appropriate, test data will be compiled on spread sheets. Data for each sample include: sample identification, sample preparation date, composition, laboratory temperature and relative humidity, and other data of interest.

All log books, photographs, notes, and other forms of raw data will remain in the custody of the SCFA and the team leader for review until the release of the log books for long term storage. A photocopy will be made at the end of each work day and stored in a secure place. All the reduced data will also be stored in the LMITCO project file. The published LMITCO reports remain on file and are available through the library system. All data will be validated by the PI by checking numbers and procedures. Raw data and procedures will be checked daily by a second person and at least twice a week by the PI.

\subsection{Test Plan}

Test plan changes are of two types:

1. Type 1 changes have an effect on the project objectives and the data quality objectives, and requires the PI's approval along with the laboratory scientist. Type 1 changes require completion of (a) the Document Action Request identifying the change, (b) redlined test plan, and (c) necessary signatures.

2. Type 2 changes do not effect the project objectives or the data quality objectives, and can be made by the laboratory scientist. Type 2 changes can be identified by redlining the test plan with the scientist's concurrence (initials).

\section{ANALYTICAL METHODS, CALIBRATION PROCEDURES, LABORATORY QUALITY CONTROL}

Instruments used for quantitative measurements will be calibrated and approved by the Standards and Calibrations Laboratory or by the manufacture. Back up material samples will be made for archival samples and display purposes and will be placed in sealed bags and labeled with date and log book serial 
number. All pertinent data for that sample will be noted in the logbook and will include sample identification number, material composition, date, time, notes, and observations.

Qualitative data will be recorded and documented through log book entries, photographic evidence, and video tapes, as appropriate.

All laboratory data and observations will be recorded in a bound, library registered laboratory notebook. It will be dated and signed daily by the person doing experiments. Entries will be QA checked and signed daily by a second person. All reagent labels will be recorded in the notebook and will be photographed for record. All laboratory activities will be photographically documented. A second bound, library registered laboratory notebook will be used to record date, time subject, and photograph film frame number for each photograph. It will also be signed daily by the person doing photographs and entries will be QA checked and signed daily by a second person.

Chemical analysis will not be conducted in this test program.

\section{DATA REDUCTION, VALIDATION AND VERIFICATION}

\subsection{Data Reduction Scheme}

Data reduction refers to the computations and calculations performed on the data. This includes computing summary statistics, standard errors, confidence limits, tests of hypothesis relative to the parameters, and model validation. Standard equations and statistically acceptable procedures will be used. When appropriate, data will be reported with statistically supported limits of uncertainty.

All bench analysis will document sample preparation activities in a bound laboratory notebook, which will serve as the primary record for subsequent data reduction. Final data reduction of analyses performed will be the responsibility of the individual compiling the final report.

\subsection{Data Validation and Acceptance}

All data will be checked for accuracy and precision at the bench by the instrument operator and laboratory managers. Data will be reviewed on a daily basis for objectivity, accuracy, and completeness by a second person in the laboratory. The PI will review the procedures and data at least twice per week for concurrence with the test plan. All data will be accepted that satisfy the quality criteria specified in this test plan. None will be accepted that do not satisfy the quality criteria specified in this test plan. 


\section{QUALITY ASSURANCE}

\subsection{Data Quality Level and Inspection Requirements}

The quality level for lab testing activities as defined by LMITCO MCP-540 for Environmental Restoration Technology (ERT) Department work is Quality Level 3. All data will be validated to Level C. Numerical data will be obtained with the best available instrumentation that the scope and budget will allow and all instrumentation will operate in the calibrated region of the operating curves.

Nonconformance will be addressed by the PI who will make a determination regarding the utility of data produced by nonconforming procedures. Normally, such data will not be used.

\subsection{Data Precision and Accuracy}

The precision and accuracy of all of the quantitative data, including mixture preparation and composition, viscosity, compressive strength, immersion, and related measurements will be assessed using measurements on four specimens of a given parameter.

\section{EQUIPMENT AND INSTRUMENTS}

The laboratory equipment required for the barrier mix formulation tests and durability tests is standard laboratory equipment to include:

- Analytical balance milligram and kilogram range

- Wet-dry cycling chamber

- Drying oven, to $110^{\circ} \mathrm{C}$

- $\quad \mathrm{pH}$ meter

- Hobart mixer

- CES compression tester

- Viscosity meter

- Slump test instrument

- Lexan tubes

- HPDE, PVC, glass tube for molds

- Variable speed stir plate and stir bars

- Glass ware. 